Document downloaded from:

http://hdl.handle.net/10251/74231

This paper must be cited as:

V.Genovés; C.Riestra; Borrachero Rosado, MV.; Eiras Fernández, JN.; Kundu, T.; Paya Bernabeu, JJ.; riestra (2015). Multimodal analysis of GRC ageing process using Nonlinear Impact Resonance acoustic Spectroscopy. Composites Part B: Engineering. 76:105-111. doi:10.1016/j.compositesb.2015.02.020.

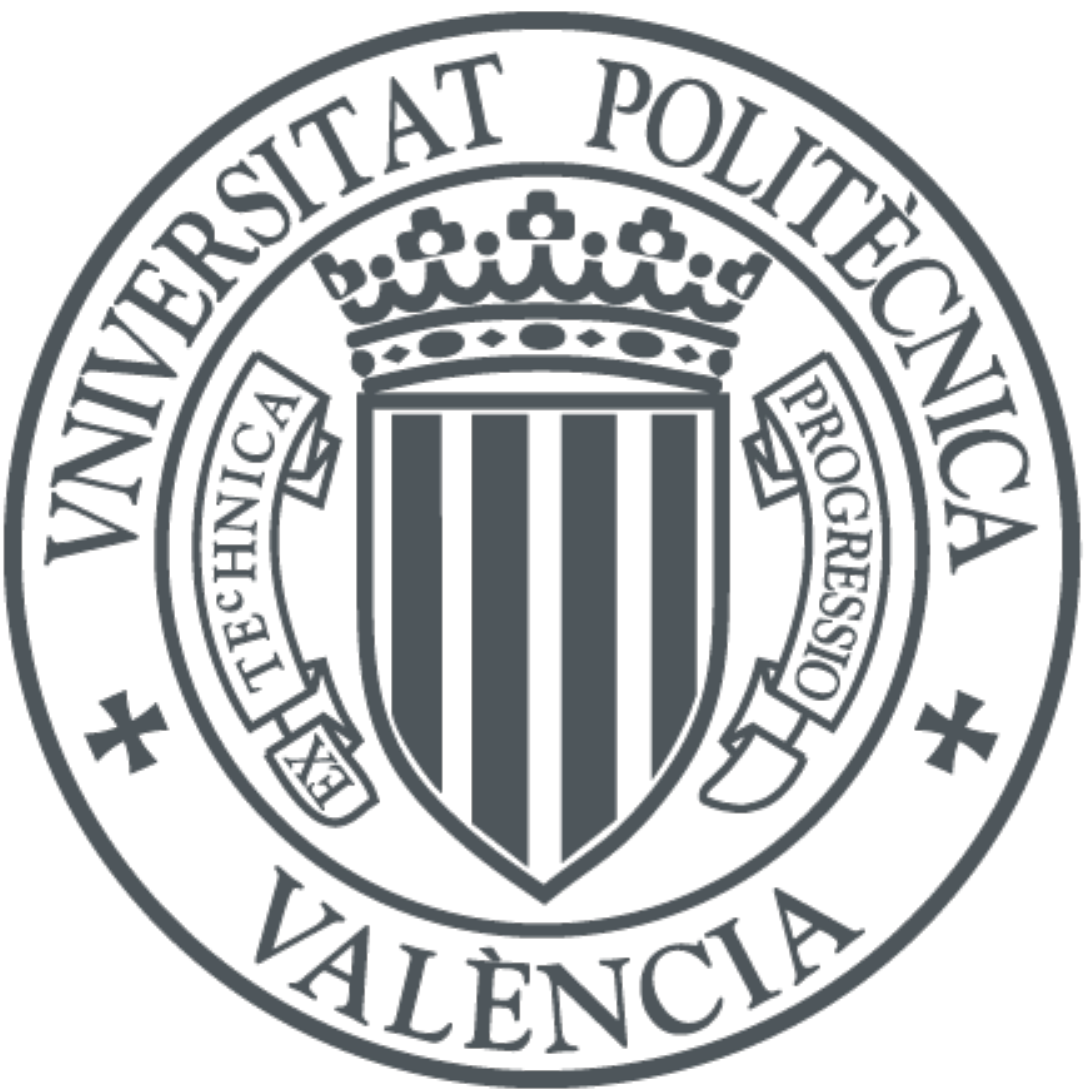

The final publication is available at

http://dx.doi.org/10.1016/j.compositesb.2015.02.020

Copyright Elsevier

Additional Information 


\title{
Multimodal analysis of GRC ageing process using Nonlinear Impact Resonance Acoustic Spectroscopy
}

\author{
V.Genovés ${ }^{\mathrm{a}, *}$, C.Riestra ${ }^{\mathrm{a}}$, M.V.Borrachero ${ }^{\mathrm{a}}$, J.Eiras ${ }^{\mathrm{a}}$, T.Kundu ${ }^{\mathrm{b}}$, J.Payá ${ }^{\mathrm{a}}$ \\ ${ }^{a}$ ICITECH, Universitat Politècnica de València, Camino de Vera, s/n 46022 Valencia, Spain \\ ${ }^{b}$ Aerospace and mechanical engineering department, University of Arizona, Tucson, AZ 85721, United States
}

\begin{abstract}
Glass fibre Reinforced Cement (GRC) is a composite material composed of Portland cement mortar with low $\mathrm{w} / \mathrm{c}$ (water/cement) ratio and high proportion of glass fibres. This material suffers from the ageing process by losing its strength with time because of its exposure to severe weather conditions. Ageing process damages the fibre surface and decreases the mechanical properties of the structural components made of this material. It reduces the elastic modulus and toughness of GRC. Fracture toughness is traditionally measured by four point bending tests. In a previous study by the authors it was observed that ageing related deterioration or damage of GRC could be monitored by Non Destructive Testing (NDT) techniques such as Non-linear Impact Resonance Acoustic Spectroscopy (NIRAS) and other ultrasonic techniques. The scope of this paper is to corroborate previous investigations and offer early damage detection capability by generating more experimental data points by optimizing location of the point of strike and thus generating more resonance vibration modes in NIRAS tests.
\end{abstract}

Keywords:

A.Ceramic-matrix composites, A.Fibres, D.Non-destructive testing, D.Non-linear acoustics

\section{Introduction}

Glass-fibre reinforce cement (GRC) is a composite material formed with Portland cement mortar with glassfibre inclusion. The matrix of this material is made from low $\mathrm{w} / \mathrm{c}$ (water/cement) ratio and high paste proportion relative to the aggregate quantity. Adding a high proportion of glass fibres to the mortar matrix improves the mechanical properties of the structural components made by this material, especially, the toughness and ductility properties. This composite plays an important role in construction of some concrete structures such as sheets, panels and other slim shapes used usually in building engineering and architecture where steel-reinforced concrete cannot be used [1].

However, due to glass composition and the nature of the Portland cement matrix, a chemical reaction occurs between cement and glass provoking the deterioration of the fibres, creating holes and coating degradation

*Corresponding author E-mail adress: genoves.gomez@gmail.com 
followed by a toughness decrease of the composite [1-3]. For this reason researchers have been developing new less aggressive matrices that improve the performance of the fibres and enhance the durability of the GRC system. Enfedaque et al. have suggested matrix modification with silica fume and metakaolin substitution, Purnell et al. studied observing the microstructure of the material using scanning electron microscopy after subjecting it to mechanical loading test $[2,4,5]$.

Behaviour of a material as it ages is generally tested by first placing specimens made of this material at high temperatures and under high humidity [6] and then performing mechanical tests to obtain its stiffness, toughness and strength.

In order to improve the material characterization and damage detection methods, researchers have been developing different non destructive testing (NDT) techniques. It is known that NDT have the capability of obtaining a number of physical properties of cementitious materials such as their dynamic Young's modulus, porosity and compressive strength [7-10]. New, NDT techniques based on non linear acoustics have been recently developed by researchers in order to detect early stage of damage in different materials [11]. Chen et al. and Leśnicki et al. were using non linear impact resonance acoustic spectroscopy (NIRAS) technique in order to detect alkali-silica reaction (ASR) damage in concrete using different types of aggregates [12, 13].

In an earlier study by the authors it was demonstrated that ageing process could be detected by acoustic resonance techniques like NIRAS more efficiently than traditional tests [14] .

The scope of this paper is to analyse the ageing process, optimizing NIRAS test method for GRC specimens to obtain more experimental data points and to evaluate the suitability of the method for monitoring ageing related degradation.

\section{Experiment}

\subsection{Materials}

GRC specimens were made according to the BS EN 1170-5 [15]. For this experiment the specimen dimension was chosen as $275 \times 50 \times 10 \mathrm{~mm}^{3}$. The specimens were cut from $350 \times 350 \times 10 \mathrm{~mm}^{3}$ mother plates.

Table 1: Tests performed on different plates

\begin{tabular}{llllllllllll}
\hline Plate & $0 \mathrm{~h}$ & $4 \mathrm{~h}$ & $8 \mathrm{~h}$ & $12 \mathrm{~h}$ & $20 \mathrm{~h}$ & $24 \mathrm{~h}$ & $33 \mathrm{~h}$ & $40 \mathrm{~h}$ & $48 \mathrm{~h}$ & $63 \mathrm{~h}$ & $90 \mathrm{~h}$ \\
\hline $\mathrm{I}$ & $\mathrm{N} / \mathrm{B} / \mathrm{S}$ & - & - & - & - & - & - & - & - & - & - \\
II & $\mathrm{N}$ & & $\mathrm{N} / \mathrm{B}$ & - & - & - & - & - & - & - & - \\
III & $\mathrm{N}$ & - & - & - & - & $\mathrm{N} / \mathrm{B}$ & - & - & - & - & - \\
IV & $\mathrm{N}$ & $\mathrm{N}$ & $\mathrm{N}$ & $\mathrm{N}$ & $\mathrm{N}$ & $\mathrm{N}$ & $\mathrm{N}$ & $\mathrm{N}$ & $\mathrm{N}$ & $\mathrm{N}$ & $\mathrm{N} / \mathrm{B} / \mathrm{S}$ \\
\multicolumn{7}{c}{$\mathrm{N}=$ NIRAS test, $\mathrm{B}=$ Bending test, $\mathrm{S}=$ SEM }
\end{tabular}

Four such mother plates were fabricated. From every mother plate 7 specimens were cut, thus 28 specimens in total were prepared. 
Table 1 shows different tests performed on the four plates. NIRAS tests were performed for different extents of ageing, SEM observations were made for undamaged and totally damaged specimens in order to see the fibre degradation, and mechanical tests were performed after $0 \mathrm{~h}, 8 \mathrm{~h}, 24 \mathrm{~h}$ and $90 \mathrm{~h}$ of ageing. Table 2 shows the proportions and information about the raw materials used to fabricate the GRC plates.

Table 2: Used dosage for one GRC plate specimen

\begin{tabular}{lll}
\hline Material & Type & Weight $[\mathrm{g}]$ \\
\hline Cement & CEM I 52.5 R & 3630 \\
Water & - & 1270.5 \\
Sand & Silica sand 0/2 & 2432 \\
Superplastizicer & Policarboxilate ether & 7 \\
Fibre & Glass AR 12 mm & 147 \\
\hline
\end{tabular}

After characterizing all specimens (from SEM, bending test and NIRAS) and identifying all resonance vibration modes the rest of the specimens were immersed in a controlled water tank at $65^{\circ} \mathrm{C}$ to age them. The tests were performed at different stages of ageing as shown in table 1.

\subsection{Modal analysis}

Because of the importance of identifying the vibration modes and obtain as many modes as possible with high amplitude, a modal extraction analysis was performed with a finite element method (FEM) software (ANSYS).

During the theoretical analysis study the specimen size influence was investigated considering four sizes of the plate: $225 \times 50 \times 10,275 \times 50 \times 10,325 \times 50 \times 20,325 \times 50 \times 30 \mathrm{~mm}^{3}$ geometries. Modal analysis results were used to optimize the point of impact and receiving sonsor locations on the specimen in order to obtain as many modes as possible on the experimental spectrum response.

Table 3: FEM calculation parameters

\begin{tabular}{llll}
\hline Ec $[\mathrm{Mpa}]$ & $v$ & $\delta\left[\mathrm{kg} / \mathrm{m}^{3}\right]$ & Range $[\mathrm{Hz}]$ \\
\hline 28000 & 0.18 & 2300 & $0-5000$ \\
\hline
\end{tabular}

Table 3 shows values used for the FEM analysis. Mechanical properties were taken from references [16] and adjusted to match the experimental results.

\subsection{NIRAS technique}

NIRAS method is a relatively new NDT technique which can detect changes in materials from the resonance frequency shifts of the vibrational modes of a specimen made from this material as the impact energy increases [17]. This change is simply due to the non-linearity of the material. This technique has been shown to be highly high sensitivity to material defects, specifically to the micro-cracks of the material. It is well-known that defects in a material can be detected from the vibrational frequency resonance values of a specimen made of that material. Distributed cracks reduce the stiffness of the specimen, and therefore, the natural frequency of the structural 
element made of that material. Besides this linear effect $(f=\sqrt{k / m}$, where $k$ is the stiffness and $m$ the mass of the specimen) cracks also change non-linear properties of the material: Those cracks form imperfect matrix and non-homogeneity zones and thus creates, for instance, pores or voids, micro pores, paste-aggregate interface and other mesoscopic effects [13, 17].

This kind of imperfections trigger non-linear effects such as change of the frequency when the impact energy is increased, non linear modulation of two waves and scalability loss. This distortion of the elastic waves is responsible for the change in the observed resonance frequency in NIRAS tests, which can be described as a non-linear hysteretic macroscopic behavior of the material itself [13].

According to the phenomenological model for hysteresis and classical non-linear constitutive relations proposed by Van Den Abeele et al.[18], the elastic modulus for a material with non-linear effects can be represented as eq 1 :

$$
E=E_{0}\left[1+\beta \epsilon+\delta \epsilon^{2}+\alpha(\Delta \epsilon+\epsilon \operatorname{sgn}(\dot{\epsilon}))\right]
$$

where $\mathrm{E}_{0}$ is the linear elastic modulus, $\beta$ and $\delta$ are the coefficients of cubic and quartic anharmonicities, $\Delta \epsilon$ is the strain amplitude variation, $\epsilon$ and $\dot{\epsilon}$ are the strain and strain rate, $\alpha$ is the measure of hysteresis, and sgn is the sign function [18]. Specimens made with these materials that follow eq. 1 change their natural vibration frequencies with the variation of the excitation energy. This non-linearity could be defined as follows (eq. 2)

$$
\frac{f_{0}-f}{f_{0}}=\alpha \Delta \epsilon
$$

where $f_{0}$ is the frequency for the low impact energy, $f$ the frequency for the high impact energy, $\alpha$ the measure of non-linearity and $\epsilon$ the deformation suffered by the specimen. In this experiment, 10 impacts were given for every NIRAS test. After collecting ten signals with different impact energies and identifying the peaks in the frequency domain a first order polynomial was fitted to obtain the $\mathrm{R}^{2}$ of the line as a measure of the reliability of the hysteretic parameter.

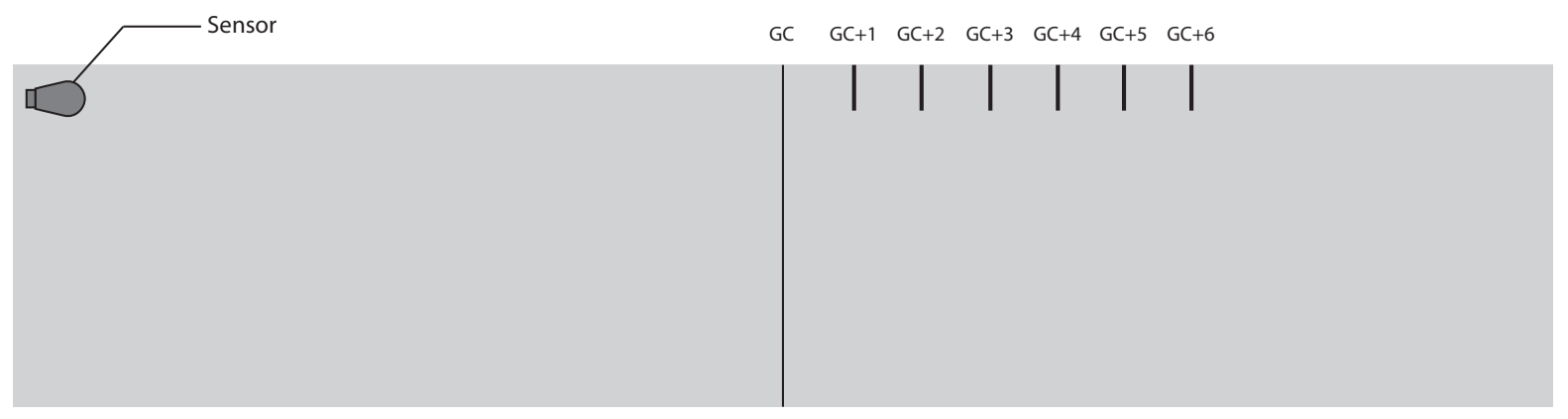

Figure 1: Point of impact layout 


\subsection{Test disposition}

In order to optimize the location of the hammer impact point, multiple points of the specimen were hit by the hammer and corresponding response spectra were recorded. Figure 1 shows different impact point locations on the specimen and the sensor location.

Figure 2 shows the test configuration. It is composed of one hammer support attached to a rigid base and both sides of the support are linked by a metallic axis that makes the impact hammer to rotate, for hitting the specimen with different levels of impact energy.

There are also two additional supports for placing the specimen in the required position when it is struck by the hammer. The specimen support frame is attached to the same rigid base where the hammer support frame is attached.

The test disposition permits the specimen vibrates without constraints (a case of free vibration).

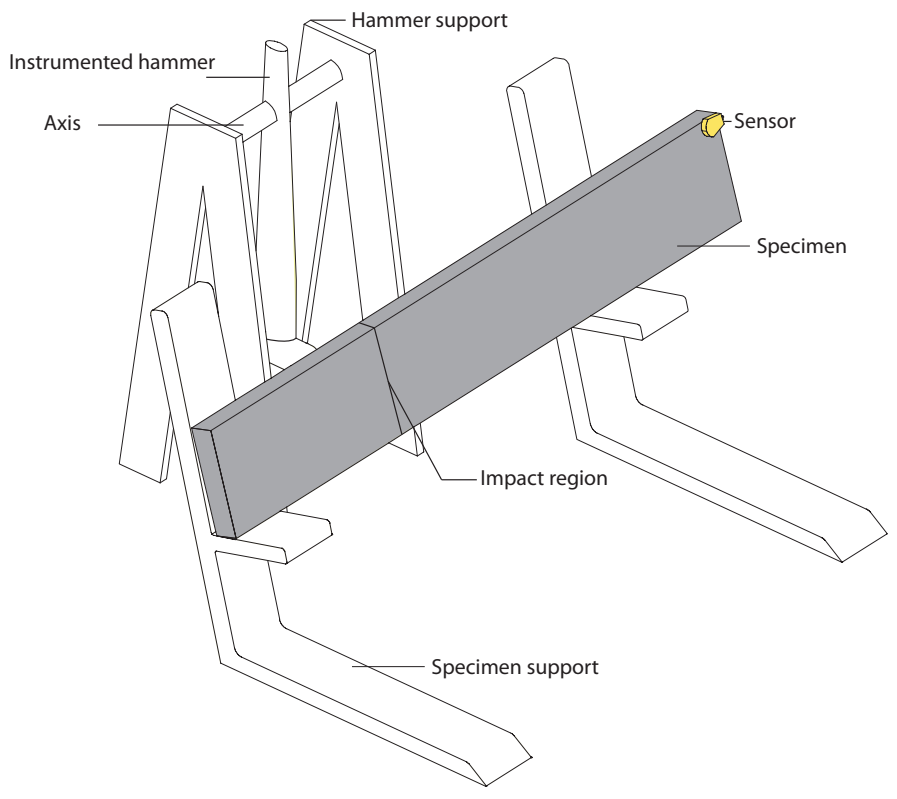

Figure 2: Tests disposition: Specimen and apparatus

After location of the hammer strike point had been optimized, the study of ageing process with this configuration began.

\section{Results and discussion}

\subsection{Modal analysis results}

As mentioned in previous sections, modal analysis was performed to see frequency response of different specimen geometries and select the best option.

More than four geometries were simulated for the modal analysis, but only the most interesting ones are plotted in figure 3. Colour code used in this figure indicates specimen's vibrational modes. Blue color is for 
flexural xy modes, red color is for torsional modes and green color is for flexural xz modes. Figure 3a shows bad spectrum distribution: some modes ( $2^{\text {nd }}$ flexural xy and $1^{\text {st }}$ torsional, $3^{\text {rd }}$ flexural $\mathrm{xy}$ and $2^{\text {nd }}$ torsional) appear too close to one another in the spectrum, leaving some wide empty frequency bands. When two modes appear too close to each other then it is a problem because then two close peaks having finite width. Figures $3 \mathrm{~b}$ and $3 \mathrm{c}$ have a good number of well-separated peaks in the spectrum, however $3 \mathrm{~b}$, have more modes to analyse and therefore is a better distribution choice. In addition, $275 \times 50 \times 10 \mathrm{~mm}^{3}$ specimens require relatively less amount of material to make. Figure $3 \mathrm{~d}$ shows only six modes in the frequency range of analysis and this specimen also needs more material and was discarded for that reason.

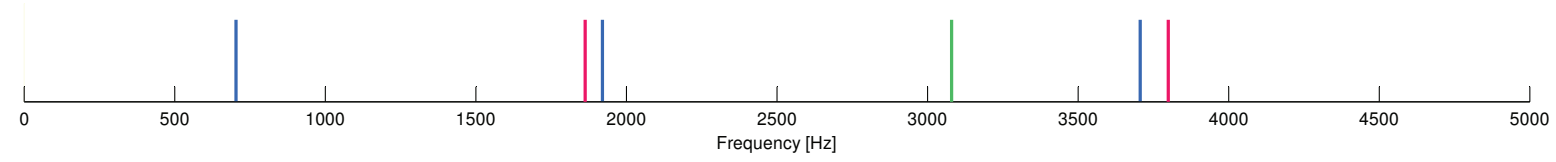

(a) $225 \times 50 \times 10 \mathrm{~mm}^{3}$ specimen

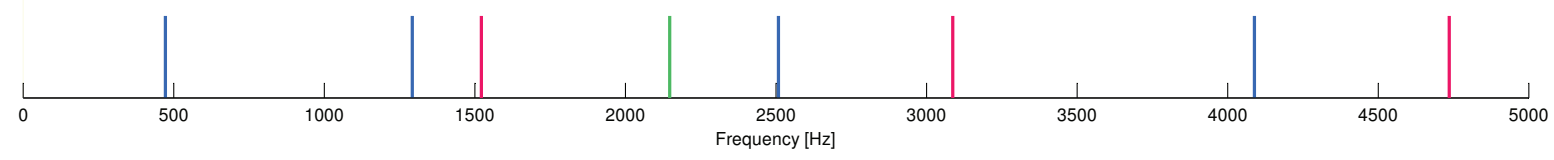

(b) $275 \times 50 \times 10 \mathrm{~mm}^{3}$ specimen

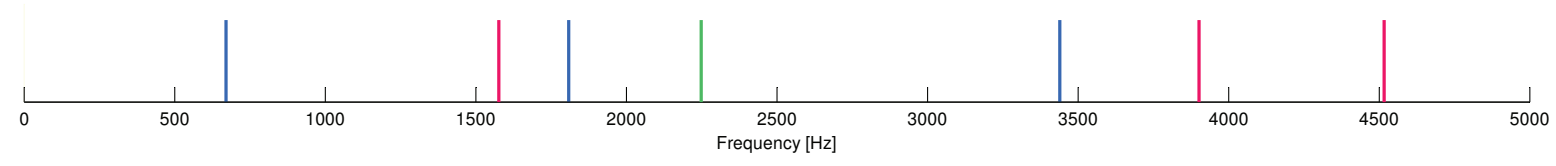

(c) $325 \times 50 \times 20 \mathrm{~mm}^{3}$ specimen

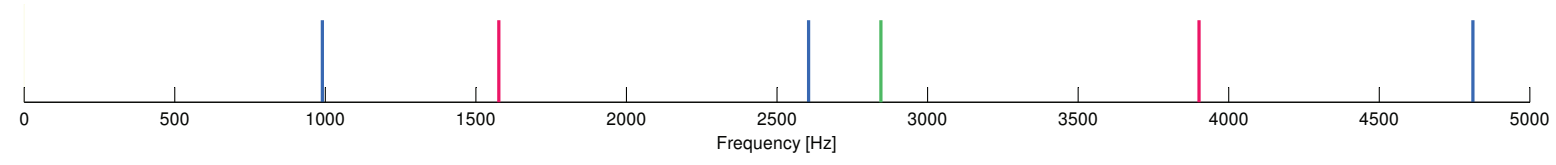

(d) $325 \times 50 \times 30 \mathrm{~mm}^{3}$ specimen

Figure 3: Modal analysis simulations done with FEM software for different specimen geometries

A complete analysis was then performed for the selected specimen geometry $275 \times 50 \times 10 \mathrm{~mm}^{3}$. Figure 4 shows the mode shapes for displacement variations for the extracted modes. From these diagrams a fixed location for the accelerometer at the corner of the specimen where the deformation is maximum was selected. This mode shape analysis gave important information about how to choose the point of impact location. Hitting at a high deformation location made the specimen capable of exciting the desired number of modes. For instance, $1^{\text {st }}$ flex $\mathrm{xz}$ (figure 4d) mode could not be excited due to the specimen disposition on the testing support (the impact direction is normal to the plane of displacement).

\subsection{Point of impact results}

In order to optimize the test method and obtain more modal experimental spectrum response, an investigation to determine the point of impact experiment was performed. It was done by varying the impact point by one 


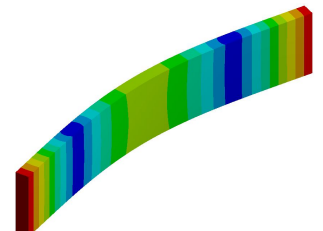

(a) $1^{\text {st }}$ flex xy: $472.3 \mathrm{~Hz}$

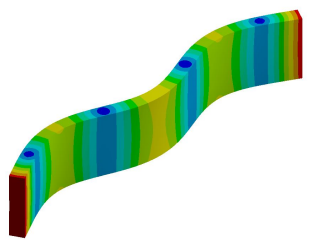

(e) $3^{r d}$ flex xy:2508.4 Hz

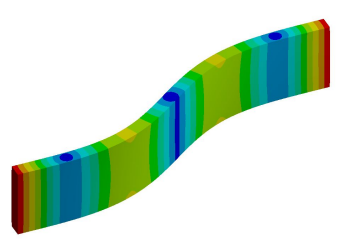

(b) $2^{\text {nd }}$ flex xy:1292.9 Hz

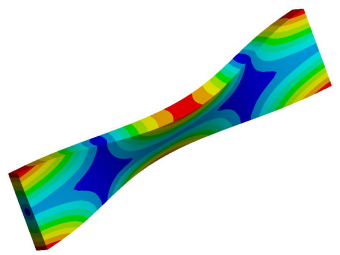

(f) $2^{\text {nd }}$ tor: $3087.8 \mathrm{~Hz}$

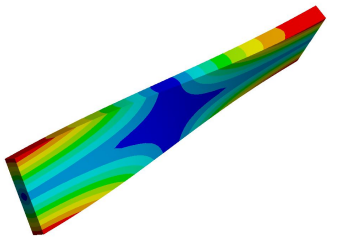

(c) $1^{\text {st }}$ tor: $1522.1 \mathrm{~Hz}$

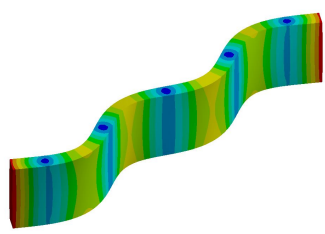

(g) $4^{\text {th }}$ flex xy: $4089.2 \mathrm{~Hz}$

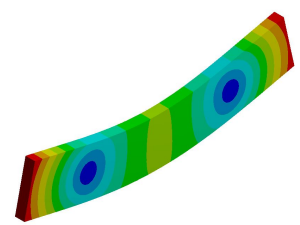

(d) $1^{\text {st }}$ flex xz:2147.2 Hz

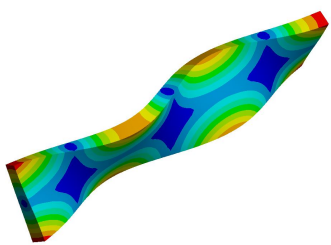

(h) $3^{\text {rd }}$ tor: $4736.2 \mathrm{~Hz}$

Figure 4: FEM total deformation modal analysis

centimetre from the geometric centre towards one end of the specimen. Response spectra for the same impact energy level for different impact locations plotted in figure 5. Impact at the geometric center of the specimen generated only a few modes. This observation can be justified from the fact that for many modes geometric center is a node position and hitting at the node position cannot generate that specific mode. Thus, impacting on geometric centre of the specimen (figure 5a) activates only three modes (first flexural, third flexural and second torsional, figures $4 \mathrm{a}, 4 \mathrm{e}$ and $4 \mathrm{f}$ ) because second flexural and first torsional (figures $4 \mathrm{~b}$ and $4 \mathrm{c}$ ) have a node (zero displacement) at that impact point.

As the impact point is moved from the geometric center, other modes start to appear. One and two centimetres offsets from the geometric centre (figures 5b and 5c) show low amplitude modes near 1000 to $1500 \mathrm{~Hz}$ frequencies. Three centimetres offset from the geometric centre (figure $5 \mathrm{~d}$ ) seems to be the most appropriate position since the modes are stable and have relatively high amplitudes. Other positions also have interesting spectral response (figures $5 \mathrm{e}, 5 \mathrm{f}$ and $5 \mathrm{~g}$ ) but were discarded because the specimen became unstable on the test support for those cases. First flexural xz (figure 4d) mode could not be excited for obvious reasons (no peaks at $2147 \mathrm{~Hz})$. 


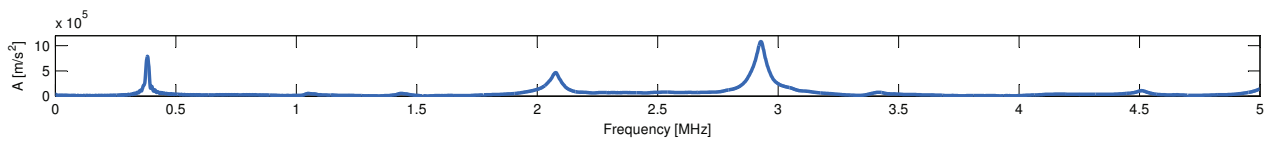

(a) Geometric center

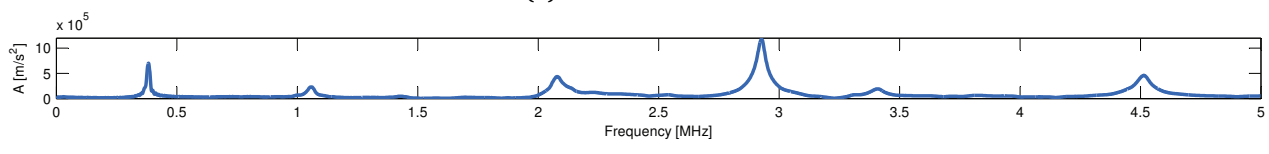

(b) $+1 \mathrm{~cm}$ offset

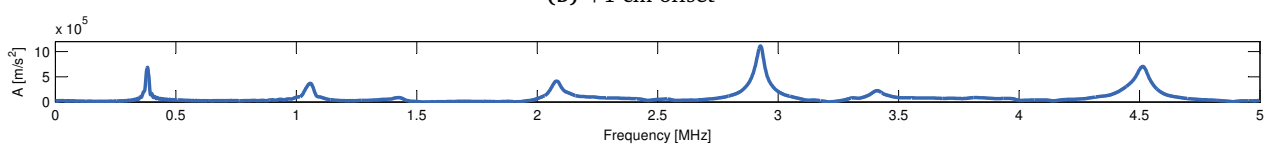

(c) $+2 \mathrm{~cm}$ offset

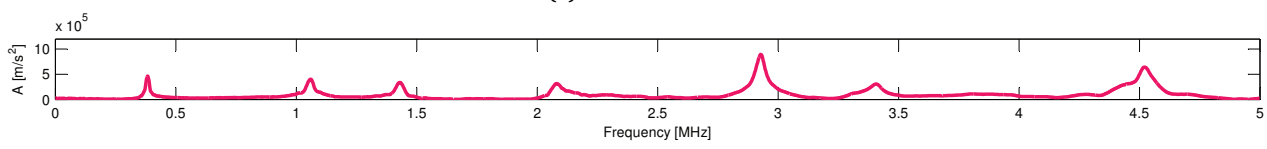

(d) $+3 \mathrm{~cm}$ offset

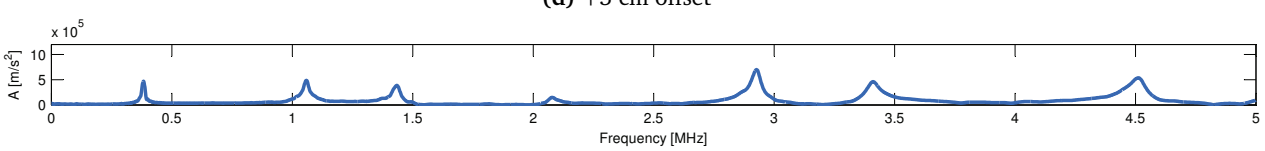

(e) $+4 \mathrm{~cm}$ offset

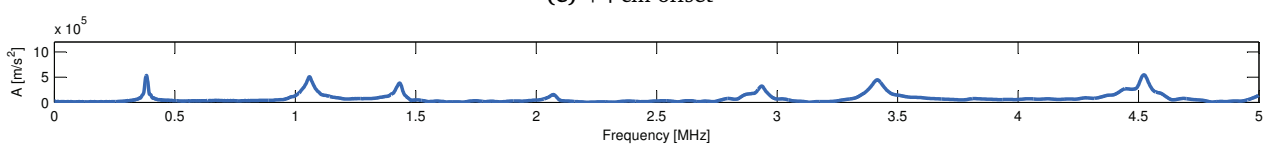

(f) $+5 \mathrm{~cm}$ offset

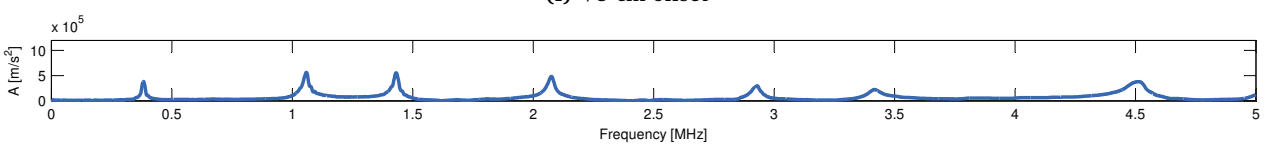

(g) $+6 \mathrm{~cm}$ offset

Figure 5: Frequency response of the same specimen for different impact locations as shown in figure 2

\subsection{Linear and non-linear results}

Table 4 shows the variations of toughness, elastic modulus and flexural strength at different stages of ageing or degradation. As can be observed, there is a remarkable decay for some of these parameters due to the fibre degradation. Note that toughness increases at the early stage of ageing because of a late hydration process due to the thermal treatment. However, during later stages of ageing, toughness decreases due to the fibres degradation. $\sigma_{\max }$ did not have any noticeable change.

Table 4: Mechanic parameters extracted from four points bending test

\begin{tabular}{llll}
\hline Hours & Toughness $[\mathrm{Nmm}]$ & $\mathrm{Ec}_{\text {flex }}[\mathrm{GPa}]$ & $\sigma_{\max }[\mathrm{MPa}]$ \\
\hline 0 & $142.45 \pm 37.1$ & $4428 \pm 534.0$ & $11.31 \pm 2.0$ \\
8 & $167.528 \pm 29.3$ & $2745.52 \pm 821.7$ & $11.08 \pm 1.3$ \\
24 & $123.77 \pm 13.7$ & $3151.85 \pm 320.5$ & $10.02 \pm 1.0$ \\
90 & $113.77 \pm 49.4$ & $3333.42 \pm 604.7$ & $10.93 \pm 1.9$ \\
\hline
\end{tabular}


The experimental and the theoretical resonance frequencies are plotted in figure 6 . The slight difference between these two series on the graph is due to the plate cutting and manufacturing. The experimental data correspond to 28 specimens after being cured at $20{ }^{\circ} \mathrm{C}$ in wet chamber for 28 days, before any ageing or fibre degradation.

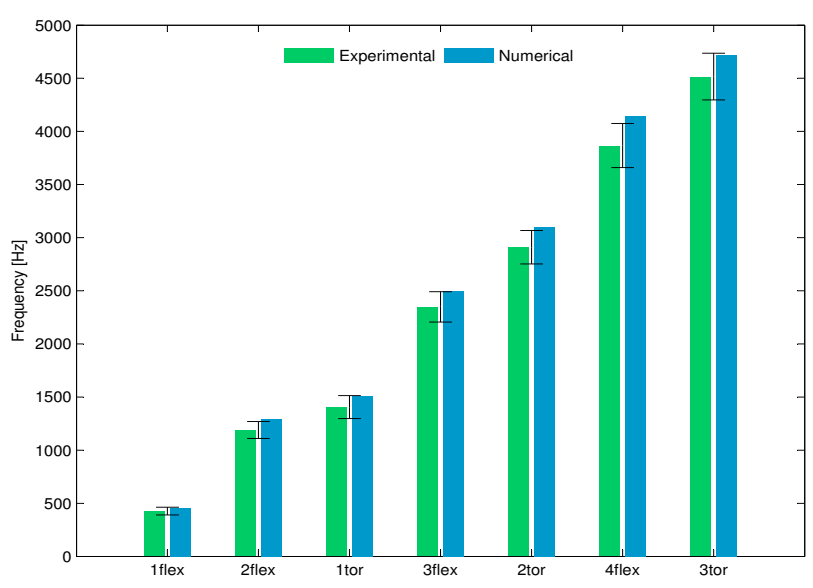

Figure 6: Theoretical and experimental frequency comparisons

As commented before, NIRAS tests were performed in order to evaluate the frequency and non linearity parameter changes due to the material degradation.

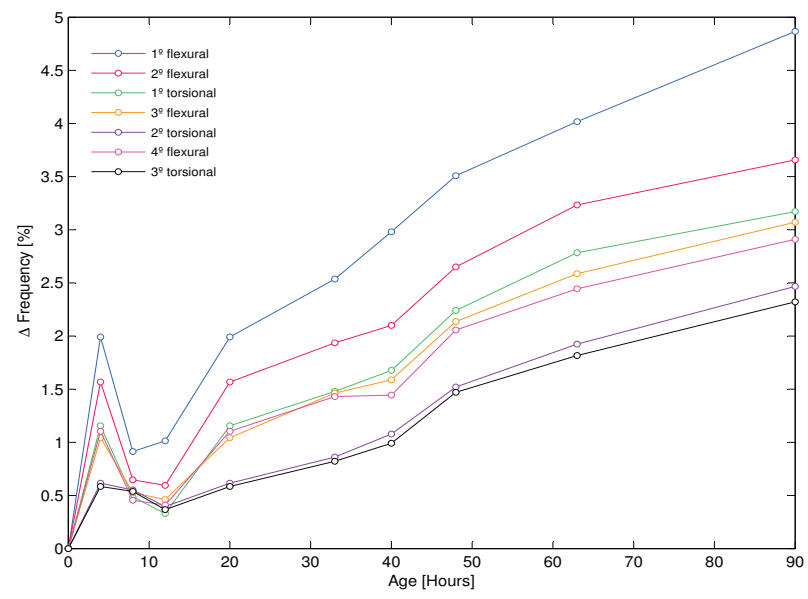

Figure 7: Frequency variation with ageing process

After computing the frequency values for every mode, the experimental data points were plotted in figure 7. 
Frequency and alpha variation ( $\Delta$ frequency and $\Delta \alpha$ ) was computed using eq. 3:

$$
\frac{P_{t}-P_{0}}{P_{0}} \cdot 100
$$

where $P_{t}$ is the parameter at $t$ time and $P_{0}$ is the parameter for the undamaged specimen at the beginning of the experiment (after 28 days of curing in the wet chamber). Table 5 shows mean values of $\alpha$ and frequency for all modes and ages.

Table 5: Mean values of frequency $[\mathrm{Hz}]$ and alpha for all ages $[\mathrm{h}]$ and modes. Standard deviations are given under each value

\begin{tabular}{|c|c|c|c|c|c|c|c|c|c|c|c|c|c|c|}
\hline \multirow[b]{2}{*}{ Age } & \multicolumn{2}{|l|}{$1^{s t}$ Flex } & \multicolumn{2}{|l|}{$2^{\text {nd }}$ Flex } & \multicolumn{2}{|l|}{$1^{s t}$ Tor } & \multicolumn{2}{|l|}{$3^{r d}$ Flex } & \multicolumn{2}{|l|}{$2^{\text {nd }}$ Tor } & \multicolumn{2}{|l|}{$4^{\text {th }}$ Flex } & \multicolumn{2}{|l|}{$3^{r d}$ Tor } \\
\hline & $\alpha$ & Freq & $\alpha$ & Freq & $\alpha$ & Freq & $\alpha$ & Freq & $\alpha$ & Freq & $\alpha$ & Freq & $\alpha$ & Freq \\
\hline \multirow[t]{2}{*}{0} & $9.4 \cdot 10^{-8}$ & 426 & $6.6 \cdot 10^{-8}$ & 1189 & $5.5 \cdot 10^{-8}$ & 1405 & $8.4 \cdot 10^{-8}$ & 2348 & $2.8 \cdot 10^{-8}$ & 2910 & $7.1 \cdot 10^{-8}$ & 3867 & $2.4 \cdot 10^{-8}$ & 4515 \\
\hline & $3.8 \cdot 10^{-8}$ & 39 & $5.5 \cdot 10^{-8}$ & 83 & $5.1 \cdot 10^{-8}$ & 115 & $1.5 \cdot 10^{-8}$ & 151 & $2.6 \cdot 10^{-8}$ & 167 & $1.5 \cdot 10^{-8}$ & 217 & $1.6 \cdot 10^{-8}$ & 234 \\
\hline \multirow[t]{2}{*}{4} & $9.9 \cdot 10^{-8}$ & 424 & $7.1 \cdot 10^{-8}$ & 1182 & $5.4 \cdot 10^{-8}$ & 1393 & $6.7 \cdot 10^{-8}$ & 2334 & $1.7 \cdot 10^{-8}$ & 2884 & $5.9 \cdot 10^{-8}$ & 3847 & $1.9 \cdot 10^{-8}$ & 4473 \\
\hline & $4.8 \cdot 10^{-8}$ & 34 & $4.9 \cdot 10^{-8}$ & 77 & $1.5 \cdot 10^{-8}$ & 107 & $2.1 \cdot 10^{-8}$ & 137 & $4.6 \cdot 10^{-8}$ & 154 & $2.3 \cdot 10^{-8}$ & 218 & $3.6 \cdot 10^{-8}$ & 2.16 \\
\hline \multirow[t]{2}{*}{8} & $1.1 \cdot 10^{-7}$ & 429 & $6.3 \cdot 10^{-8}$ & 1190 & $2.9 \cdot 10^{-8}$ & 1401 & $5.3 \cdot 10^{-8}$ & 2344 & $1.3 \cdot 10^{-8}$ & 2895 & $8.3 \cdot 10^{-8}$ & 3857 & $1.8 \cdot 10^{-8}$ & 4487 \\
\hline & $6.4 \cdot 10^{-8}$ & 35 & $3.0 \cdot 10^{-8}$ & 77 & $1.2 \cdot 10^{-8}$ & 109 & $3.1 \cdot 10^{-8}$ & 140 & $5.0 \cdot 10^{-8}$ & 157 & $2.0 \cdot 10^{-8}$ & 211 & $2.5 \cdot 10^{-8}$ & 221 \\
\hline \multirow[t]{2}{*}{12} & $1.2 \cdot 10^{-7}$ & 428 & $5.9 \cdot 10^{-8}$ & 1191 & $2.9 \cdot 10^{-8}$ & 1401 & $5.7 \cdot 10^{-8}$ & 2349 & $1.5 \cdot 10^{-8}$ & 2898 & $3.6 \cdot 10^{-8}$ & 3862 & $1.1 \cdot 10^{-8}$ & 4497 \\
\hline & $6.2 \cdot 10^{-8}$ & 34 & $3.0 \cdot 10^{-8}$ & 79 & $1.2 \cdot 10^{-8}$ & 110 & $2.0 \cdot 10^{-8}$ & 205 & $2.5 \cdot 10^{-8}$ & 157 & - & 201 & - & 215 \\
\hline \multirow[t]{2}{*}{20} & $8.7 \cdot 10^{-8}$ & 435 & $3.8 \cdot 10^{-8}$ & 1207 & $1.2 \cdot 10^{-8}$ & 1420 & $3.7 \cdot 10^{-8}$ & 2372 & $8.8 \cdot 10^{-9}$ & 2921 & - & 3881 & - & 4530 \\
\hline & $4.6 \cdot 10^{-8}$ & 35 & $1.1 \cdot 10^{-8}$ & 78 & $4.3 \cdot 10^{-8}$ & 107 & $1.9 \cdot 10^{-8}$ & 135 & $2.5 \cdot 10^{-9}$ & 157 & - & 201 & - & 215 \\
\hline \multirow[t]{2}{*}{24} & $7.8 \cdot 10^{-8}$ & 437 & $3.6 \cdot 10^{-8}$ & 1210 & $1.6 \cdot 10^{-8}$ & 1424 & $3.1 \cdot 10^{-8}$ & 2380 & $7.9 \cdot 10^{-9}$ & 2931 & - & 3917 & - & 4549 \\
\hline & $4.3 \cdot 10^{-8}$ & 37 & $1.6 \cdot 10^{-8}$ & 76 & $1.6 \cdot 10^{-8}$ & 109 & $8 \cdot 10^{-9}$ & 139 & $2.5 \cdot 10^{-9}$ & 155 & - & 201 & - & 216 \\
\hline \multirow[t]{2}{*}{33} & $7.2 \cdot 10^{-8}$ & 439 & $3.5 \cdot 10^{-8}$ & 1213 & $1.4 \cdot 10^{-8}$ & 1428 & $2.7 \cdot 10^{-8}$ & 2385 & $7.7 \cdot 10^{-9}$ & 2939 & - & 3922 & - & 4556 \\
\hline & $3.5 \cdot 10^{-8}$ & 35 & $1.9 \cdot 10^{-8}$ & 77 & $6.2 \cdot 10^{-8}$ & 135 & $2.1 \cdot 10^{-9}$ & 153 & $2.5 \cdot 10^{-9}$ & 202 & - & 214 & & \\
\hline \multirow[t]{2}{*}{40} & $5.1 \cdot 10^{-8}$ & 441 & $3.6 \cdot 10^{-8}$ & 1220 & $1.5 \cdot 10^{-8}$ & 1435 & $2.8 \cdot 10^{-8}$ & 2397 & $5.8 \cdot 10^{-9}$ & 2952 & - & 3951 & - & 4581 \\
\hline & $3.1 \cdot 10^{-8}$ & 36 & $1.7 \cdot 10^{-8}$ & 77 & $2.4 \cdot 10^{-8}$ & 102 & $8.7 \cdot 10^{-9}$ & 136 & $9.0 \cdot 10^{-9}$ & 1542 & - & 197 & - & 209 \\
\hline \multirow[t]{2}{*}{48} & $6.2 \cdot 10^{-8}$ & 443 & $2.3 \cdot 10^{-8}$ & 1226 & $1.3 \cdot 10^{-8}$ & 1443 & $2.7 \cdot 10^{-8}$ & 2408 & $4.5 \cdot 10^{-9}$ & 2965 & - & 3963 & - & 4596 \\
\hline & $4.4 \cdot 10^{-8}$ & 34 & $1.4 \cdot 10^{-8}$ & 78 & $1.0 \cdot 10^{-8}$ & 110 & $8.6 \cdot 10^{-9}$ & 134 & $2.1 \cdot 10^{-8}$ & 151 & - & 196 & - & 210 \\
\hline \multirow[t]{2}{*}{63} & $4.1 \cdot 10^{-8}$ & 446 & $2.4 \cdot 10^{-8}$ & 1231 & $1.2 \cdot 10^{-8}$ & 1450 & $1.3 \cdot 10^{-8}$ & 2419 & $5.4 \cdot 10^{-9}$ & 2981 & - & 3978 & - & 4619 \\
\hline & $1.9 \cdot 10^{-8}$ & 34 & $9.2 \cdot 10^{-9}$ & 76 & $1.5 \cdot 10^{-9}$ & 103 & $1.4 \cdot 10^{-8}$ & 134 & $7.9 \cdot 10^{-9}$ & 151 & - & 169 & - & 208 \\
\hline \multirow[t]{2}{*}{90} & $1.4 \cdot 10^{-7}$ & 446 & $2.3 \cdot 10^{-8}$ & 1233 & $1.2 \cdot 10^{-8}$ & 1451 & $1.9 \cdot 10^{-8}$ & 2420 & $6.1 \cdot 10^{-9}$ & 2982 & - & 3980 & - & 4620 \\
\hline & $3.2 \cdot 10^{-8}$ & 38 & $7.35 \cdot 10^{-9}$ & 75 & $8.5 \cdot 10^{-9}$ & 102 & $7.7 \cdot 10^{-9}$ & 134 & $1.8 \cdot 10^{-9}$ & 149 & - & 194 & - & 206 \\
\hline
\end{tabular}

Figure 7 shows frequency increase for all modes. It is important to note that the low frequency modes show more relative variation than the high frequency modes. It is also noted that all modes in the range of our study have the same tendency or behaviour. During the early stages of ageing there is a slight decrease of the frequency variation which coincides with that shown in the table 4 which then stabilizes over time. Then it shows monotonic increase. After monitoring all resonance frequency modes, it is concluded that monitoring one mode is sufficient for defining the frequency variation during the ageing process.

Non-linearity parameter $\alpha$ was computed using equation 2. Figure 8 shows the $\alpha$ variation as the specimen ages. With ageing the percentage change of this parameter is much higher than the linear parameter. Clearly hysteretic parameter is more sensitive to ageing than the linear parameters. One can note that when the age of degradation increases, for most modes the variation of the hysteretic parameter monotonically increases.

$2^{\text {nd }}$ flexural, $1^{\text {st }}$ torsional, $3^{\text {rd }}$ flexural and $2^{\text {nd }}$ torsional modes show similar behaviour. Generally, when the vibrational mode is at relatively high frequencies, the non linearity parameter derived from that mode is more sensitive to ageing. However signal strengths for $4^{\text {th }}$ flexural and $3^{\text {rd }}$ torsional modes were too weak to generate 


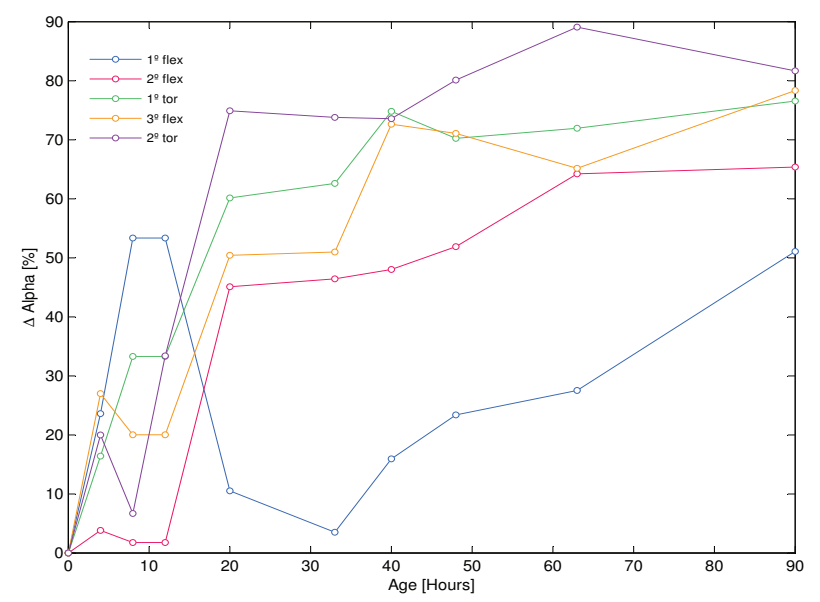

Figure 8: Non-linearity parameter variation with ageing

consistent and reliable results.

\subsection{SEM observations}

In order to see the physical condition of the fibres, scanning electron microscopy images were taken at different magnifications (figure 9).

The images were taken for two different states as mentioned in table 1 , at the beginning of the ageing process and at the end (90 hours under wet and warm conditions of ageing).

Figure 9a is a $x 200$ magnification of the fibres embedded in the cement matrix 28 days after setting. The fibres were clean and their surfaces were smooth. After 90 hours of ageing similar specimen was analysed under SEM (figure 9b) and a new layer of new products over the fibres were noticed. In x6000 magnification images the smooth surface condition can be clearly seen. Figure $9 \mathrm{c}$ shows the initial state of the fibre with the intact surface and figure $9 \mathrm{~d}$ shows a deteriorated fibre with small voids and damaged surface.

\section{Conclusions}

In this study, it has been corroborated that NIRAS is a suitable technique to evaluate ageing process for GRC specimens. Different vibrational modes have been evaluated over a frequency range in order to compare the variations of linear and non-linear parameters with ageing. It is observed that non linear parameters are more sensitive to ageing than linear parameters. Scanning electron microscopy and four point bending tests corroborated NDE observations.

\section{Acknowledgments}

The authors acknowledge the financial support of the Ministerio de Ciencia e Innovación MICINN, Spain, and FEDER funding (Ondacem Project: BIA 2010-19933). 


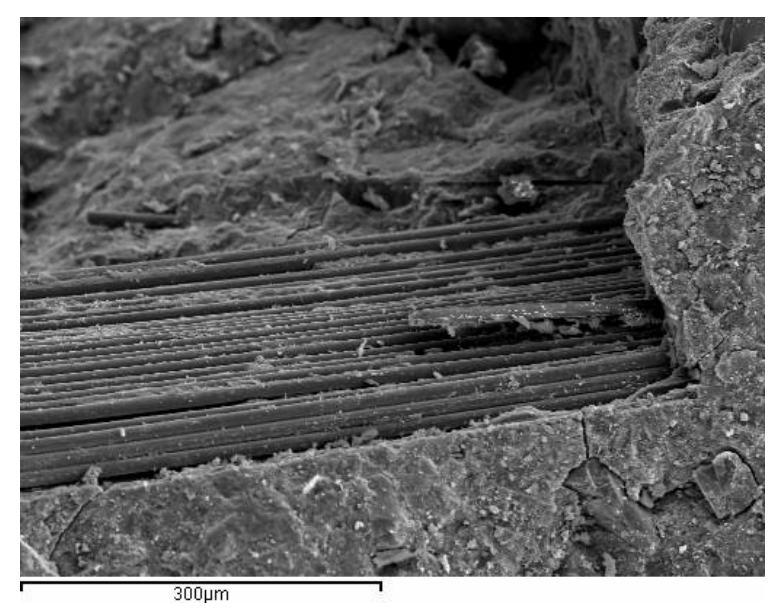

(a) Unaged fibre x200 magnification

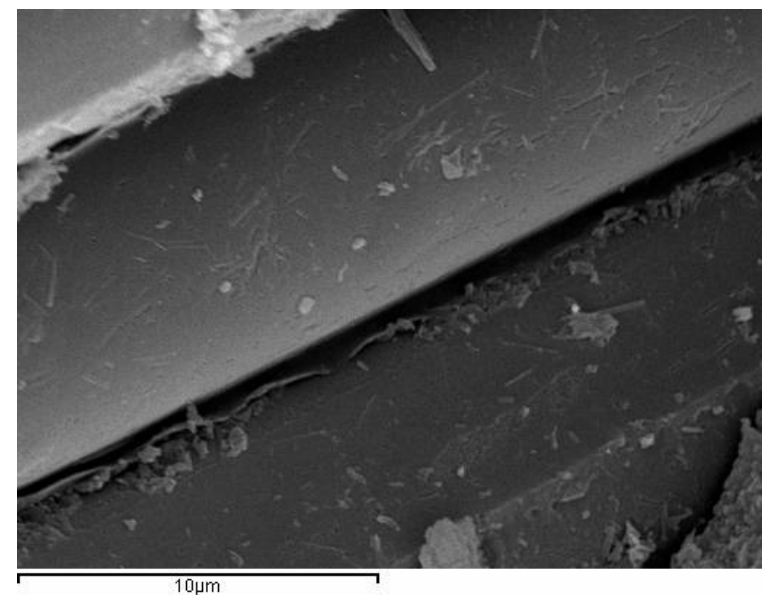

(c) Unaged fibre x6000 magnification

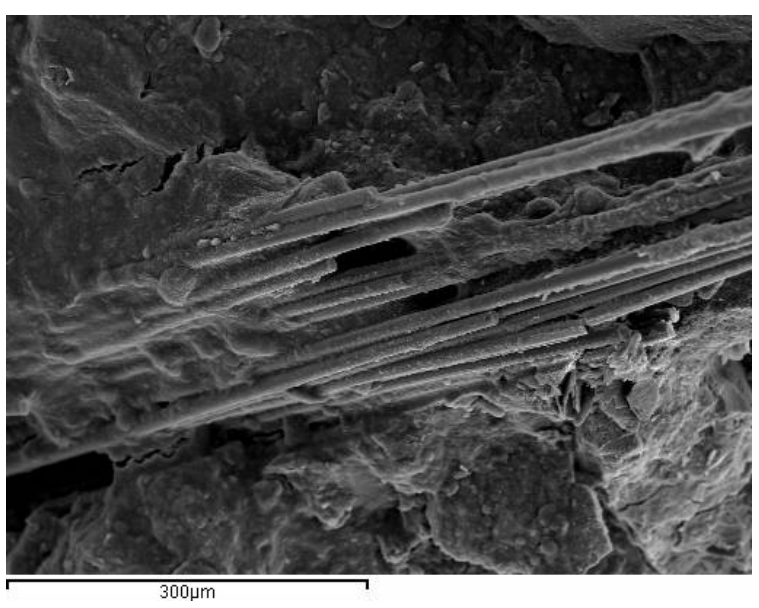

(b) 90 hours aged fibre $\mathrm{x} 200$ magnification

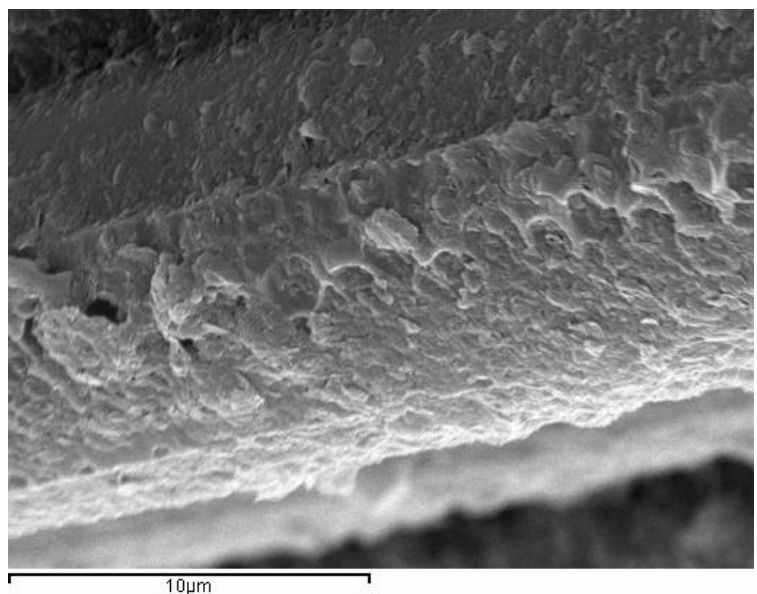

(d) 90 hours aged fibre x6000 magnification

Figure 9: SEM images of unaged and aged specimens

\section{References}

[1] A. Bentur, S. Mindess, Fibre Reinforced Cementitious Composites, Second Edition, Modern Concrete Technology, Taylor \& Francis, 2006.

[2] P. Purnell, N. Short, C. Page, A. Majumdar, P. Walton, Accelerated ageing characteristics of glass-fibre reinforced cement made with new cementitious matrices, Composites Part A: Applied Science and Manufacturing 30 (9) (1999) 1073-1080.

[3] K. Kopecskó, Durability of Glass Fibres, in: 6th RILEM Symposium on Fibre Reinforced Concrete, RILEM publications, 585-594, 2004.

[4] A. Enfedaque, D. Cendón, F. Gálvez, V. Sánchez-Gálvez, Analysis of glass fiber reinforced cement (GRC) fracture surfaces, Construction and Building Materials 24 (7) (2010) 1302-1308.

[5] P. Purnell, N. R. Short, C. L. Page, A. J. Majumdar, Microstructural observations in new matrix glass fibre reinforced cement, Cement \& Concrete Research 30 (May 1999) (2000) 1747-1753.

[6] A. Enfedaque, L. S. Paradela, V. Sánchez-Gálvez, An alternative methodology to predict aging effects on the mechanical properties of glass fiber reinforced cements (GRC), Construction and Building Materials 27 (1) (2012) 425-431.

[7] J. A. Bogas, M. G. Gomes, A. Gomes, Compressive strength evaluation of structural lightweight concrete by non-destructive ultrasonic pulse velocity method, Ultrasonics 53 (5) (2013) $962-972$.

[8] V. Malhotra, N. Carino, Handbook on Nondestructive Testing of Concrete Second Edition, Taylor \& Francis, 2003.

[9] D. Breysse, G. Klysz, X. Dérobert, C. Sirieix, J. Lataste, How to combine several non-destructive techniques for a better assessment of concrete structures, Cement and Concrete Research 38 (6) (2008) $783-793$.

[10] Y. Ito, T. Uomoto, Nondestructive testing method of concrete using impact acoustics, NDT \& E International 30 (4) (1997) 217 - 222.

[11] K.-y. Jhang, Nonlinear Ultrasonic Techniques for Non- destructive Assessment of Micro Damage in Material : A Review, International journal of precision engineering and manufacturing 10 (1) (2009) 123-135. 
[12] J. Chen, A. R. Jayapalan, J.-Y. Kim, K. E. Kurtis, L. J. Jacobs, Rapid evaluation of alkali-silica reactivity of aggregates using a nonlinear resonance spectroscopy technique, Cement and Concrete Research 40 (6) (2010) 914-923.

[13] K. J. Leśnicki, J.-Y. Kim, K. E. Kurtis, L. J. Jacobs, Characterization of ASR damage in concrete using nonlinear impact resonance acoustic spectroscopy technique, NDT \& E International 44 (8) (2011) 721-727.

[14] J. N. Eiras, T. Kundu, M. Bonilla, J. Payá, Nondestructive Monitoring of Ageing of Alkali Resistant Glass Fiber Reinforced Cement (GRC), Journal of Nondestructive Evaluation 32 (3) (2013) 300-314.

[15] B. Standard, Precast concrete products - Test method for glass-fibre reinforced cement - Part 5. Measuring bending strength, 'Complete bending test' method., 1998.

[16] F. de Larrard, Concrete Mixture Proportioning: A Scientific Approach, Modern Concrete Technology, Taylor \& Francis, 2005.

[17] J. Chen, J.-Y. Kim, K. E. Kurtis, L. J. Jacobs, Theoretical and experimental study of the nonlinear resonance vibration of cementitious materials with an application to damage characterization., The Journal of the Acoustical Society of America 130 (5) (2011) $2728-37$.

[18] K. E.-A. Van Den Abeele, P. A. Johnson, A. Sutin, Nonlinear Elastic Wave Spectroscopy (NEWS) Techniques to Discern Material Damage, Part II, Research in Nondestructive Evaluation 12 (1) (2000) 17-30. 